\title{
Direct transformation of aldehydes to nitriles using iodine in ammonia water
}

\author{
Sanjay Talukdar, Jue-Liang Hsu, Tzu-Chi Chou and Jim-Min Fang* \\ Department of Chemistry, National Taiwan University, Taipei 106, Taiwan, Republic of China
}

Received 29 November 2000; accepted 30 November 2000

\begin{abstract}
Treatment of aromatic, heterocyclic, aliphatic, conjugated, and polyhydroxy aldehydes with iodine in ammonia water at room temperature for a short period gave the corresponding nitriles in high yields. C 2001 Elsevier Science Ltd. All rights reserved.
\end{abstract}

Formation of nitriles from the corresponding aldehydes is an important functional group transformation. ${ }^{1}$ Many methods involve the initial conversion of alde- hydes to aldoximes, which are subjected to dehydration to give nitriles. ${ }^{2}$ Direct conversion of aldehydes into nitriles without isolation of nitrogen-containing inter-

Table 1. Conversion of aldehydes to nitriles by using iodine in ammonia water

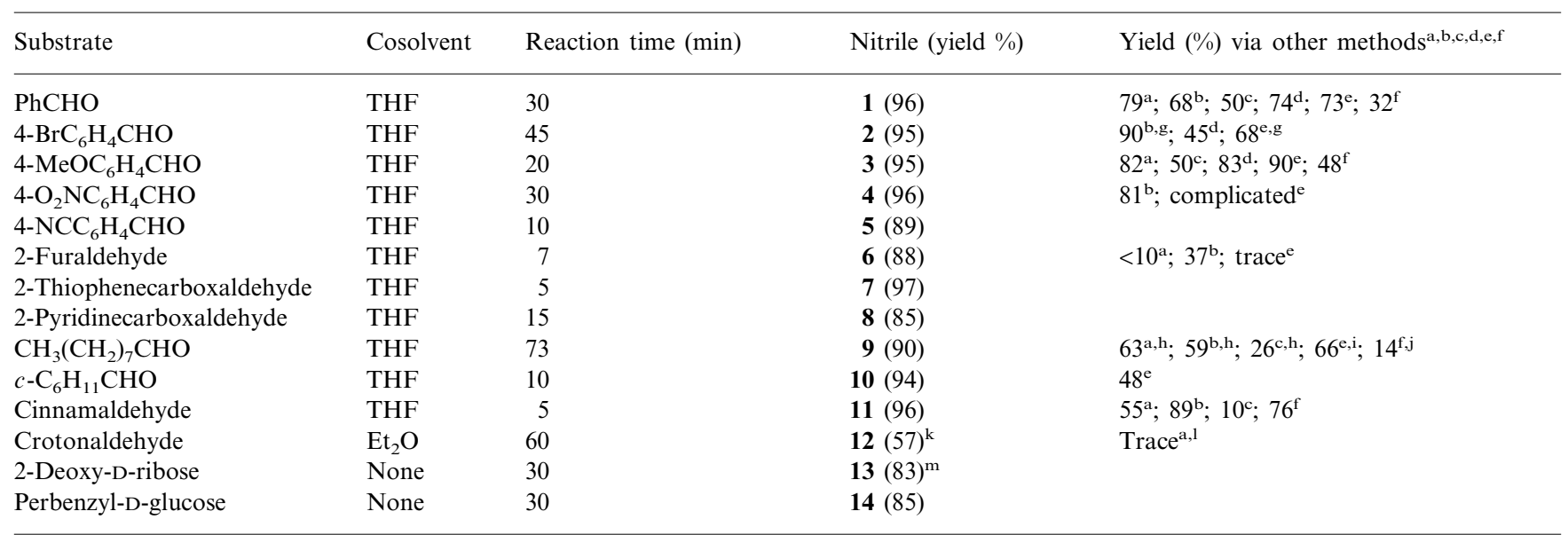

${ }^{a}$ Method A (Ref. 6a) uses $\mathrm{NH}_{3} / \mathrm{O}_{2} / \mathrm{CuCl}_{2} \cdot 2 \mathrm{H}_{2} \mathrm{O} / \mathrm{MeONa}$ in $\mathrm{MeOH}$.

${ }^{b}$ Method B (Ref. 6b) uses $\mathrm{NH}_{3} / \mathrm{Pb}(\mathrm{OAc})_{4}$ in dry benzene.

${ }^{c}$ Method $\mathrm{C}$ (Ref. 6c) uses $\mathrm{NH}_{3} / \mathrm{I}_{2} / \mathrm{MeONa}$ in $\mathrm{MeOH}$.

${ }^{\mathrm{d}}$ Method D (Ref. 6d) uses $\mathrm{NH}_{3} / \mathrm{S}_{8} / \mathrm{NaNO}_{2}$.

${ }^{\text {e }}$ Method E (Ref. 6e) uses $\mathrm{NH}_{3} / \mathrm{KI} / \mathrm{MeONa}$ in $\mathrm{MeOH}$ on electrooxidation.

${ }^{\mathrm{f}}$ Method $\mathrm{F}$ (Ref. 6f) uses $\mathrm{NH}_{3} / \mathrm{H}_{2} \mathrm{O}_{2} / \mathrm{CuCl}$ in 2-propanol.

${ }^{g}$ The yield for the reaction of $4-\mathrm{ClC}_{6} \mathrm{H}_{4} \mathrm{CHO}$.

${ }^{\mathrm{h}}$ The yield for the reaction of heptanenitrile.

${ }^{i}$ The yield for the reaction of octanenitrile.

${ }^{\mathrm{j}}$ The yield for the reaction of undecanenitrile.

${ }^{\mathrm{k}}$ Crotononitrile was the exclusive product according to the ${ }^{1} \mathrm{H}$ NMR analysis. Due to high volatility of crotononitrile, Et ${ }_{2} \mathrm{O}$ was used as the solvent instead of THF. The isolated yield decreased to $57 \%$ on evaporation.

${ }^{1}$ The result for the reaction of acrylonitrile.

${ }^{\mathrm{m}}$ The yield for the peracetylation derivative.

Keywords: aldehydes; nitriles; solvents and solvent effects.

* Corresponding author. Fax: (886-2)-2363-6359; e-mail: jmfang@mail.ch.ntu.edu.tw 
mediates has also been explored. ${ }^{3}$ In most cases, aromatic aldehydes are preferably converted to aromatic nitriles, whereas the transformations of enolizable aliphatic aldehydes often give unsatisfactory yields of aliphatic nitriles. The problem can be somewhat circumvented by using less available reagents ${ }^{4}$ (e.g. sulfimide) or unconventional approaches ${ }^{5}$ (e.g. microwave irradiation).

The use of ammonia combined with appropriate oxidants is considered as an expedient method for the transformation of aliphatic and aromatic aldehydes to their corresponding nitriles. Indeed, six processes (methods $\mathrm{A}-\mathrm{F})^{6}$ using such an approach have been reported (Table 1). Method $\mathrm{A}^{6 \mathrm{a}}$ is conducted by stirring an appropriate aldehyde with $\mathrm{NH}_{3}$ and $\mathrm{O}_{2}$ in $\mathrm{MeOH}$ using $\mathrm{CuCl}_{2}$ and $\mathrm{MeONa}$ as the promoters. This method provides modest yields $(55-82 \%)$ of aromatic and aliphatic nitriles, but low yields $(<10 \%)$ of acrylonitrile and furonitrile. Method $\mathrm{B}^{6 \mathrm{~b}}$ is performed in dry benzene by slow bubbling with $\mathrm{NH}_{3}$ gas and the portionwise addition of $\mathrm{Pb}(\mathrm{OAc})_{4}$ in a simultaneous manner. This procedure is tedious, and only small-scale reactions are demonstrated to give benzonitrile $(68 \%)$, furonitrile $(37 \%)$, and heptanenitrile $(59 \%)$. Using method $\mathrm{C},{ }^{6 c}$ benzonitrile $(50 \%), p$-chlorobenzonitrile (68\%), $p$-methoxybenzonitrile $(50 \%)$, cinnamononitrile $(10 \%)$, and heptanenitrile $(26 \%)$ are obtained from their corresponding aldehydes on treating with iodine and MeONa in $\mathrm{NH}_{3}$ gas saturated $\mathrm{MeOH}$ solution. This method is complicated by the presence of $\mathrm{MeONa}$ to give some methyl esters. Method $\mathrm{D},{ }^{6 \mathrm{~d}}$ using elemental sulfur and $\mathrm{NaNO}_{2}$ in liquid $\mathrm{NH}_{3}$ at $100^{\circ} \mathrm{C}$, is limited to the transformation of aromatic aldehydes. Method $\mathrm{E}^{6 \mathrm{e}}$ converts aldehydes to nitriles by electrooxidation in methanolic $\mathrm{NH}_{3}$ solution containing $\mathrm{KI}$ and $\mathrm{MeONa}$. This method fails to prepare $p$-nitrobenzonitrile or furonitrile due to complications from other reactions. Using method $\mathrm{F}^{6 \mathrm{ff}}$ a mixture of aldehyde and $\mathrm{H}_{2} \mathrm{O}_{2}$ (50\% solution) are slowly added (dropwise over 2.5-4 h) into $\mathrm{NH}_{3}$ gas saturated 2-propanol solution containing $\mathrm{CuCl}$. This method is applicable to large-scale reactions (e.g. $1.5 \mathrm{~mol}$ ) by using excessive amounts of $\mathrm{H}_{2} \mathrm{O}_{2}$ (e.g. $3.35 \mathrm{~mol}$ ) with cautious cooling. Benzaldehydes and conjugated aldehydes are thus converted to the corresponding nitriles in variable yields $(32-87 \%)$, as shown by the six examples. However, the reaction of enolizable aldehydes (undecanal and citronellal) is inefficient, giving the nitrile products in low yields (14 and $8 \%$, respectively, according to the GC analyses).

$$
\mathrm{R}-\mathrm{C}_{\mathrm{H}}^{\prime \prime \mathrm{O}} \stackrel{\mathrm{I}_{2} \text {, aq. } \mathrm{NH}_{3} \text {, r.t. }}{\longrightarrow} \mathrm{R}-\mathrm{C} \equiv \mathrm{N}
$$

$$
\begin{aligned}
& 1 \mathrm{R}=\mathrm{C}_{6} \mathrm{H}_{5} \\
& 4 \mathrm{R}=p-\mathrm{O}_{2} \mathrm{NC}_{6} \mathrm{H}_{4} \\
& 2 \mathrm{R}=p-\mathrm{BrC}_{6} \mathrm{H}_{4} \\
& 3 \mathrm{R}=p-\mathrm{MeOC}_{6} \mathrm{H}_{4} \\
& 7 \mathrm{R}=2 \text {-thienyl } \\
& 5 \mathrm{R}=p-\mathrm{NCC}_{6} \mathrm{H}_{4} \\
& 6 \mathrm{R}=2 \text {-furyl } \\
& 10 \mathrm{R}=\text { cyclohexyl } \\
& 8 \mathrm{R}=2 \text {-pyridyl } \\
& 9 \mathrm{R}=\mathrm{Me}\left(\mathrm{CH}_{2}\right)_{7} \\
& 11 \mathrm{R}=\mathrm{PhCH}=\mathrm{CH} \\
& 12 \mathrm{R}=\mathrm{MeCH}=\mathrm{CH}
\end{aligned}
$$

On the basis of $\mathrm{NH}_{3}$ /oxidant protocols, we wish to develop a practical and environmentally benign method for direct transformation of aldehydes to nitriles. We found that treatment of various aldehydes with iodine
(1.1 molar proportions) in ammonia water $(28 \%$ solution) at room temperature for a short period afforded the desired nitriles in very high yields (Eq. (1) and Table 1). According to the previous reports, ${ }^{6 e, 7}$ we speculated that the reaction proceeded via oxidation of aldimine with iodine to give an $N$-iodo aldimine intermediate, which eliminated an HI molecule in ammonia solution to afford the nitrile product. The aldehydes examined in this study included benzaldehydes, heterocyclic aromatic aldehydes, $\alpha, \beta$-unsaturated aldehydes, aliphatic aldehydes, and saccharide aldehydes.

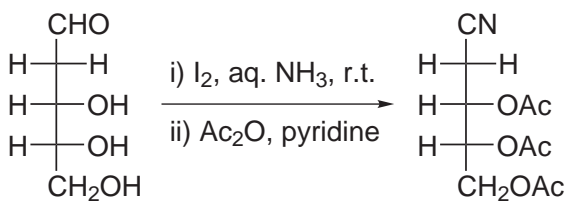

13

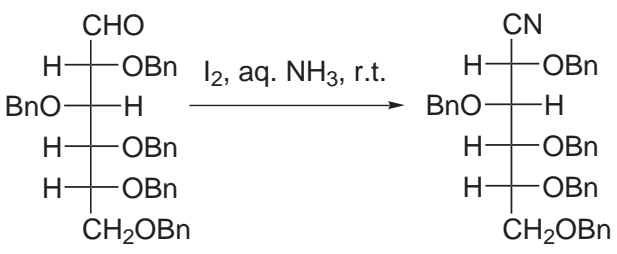

14

The following procedure is typical. Iodine $(1.1 \mathrm{mmol})$ was added to a stirring solution of aldehyde $(1 \mathrm{mmol})$ in ammonia water $(10 \mathrm{~mL}$ of $28 \%$ solution) and THF (1 $\mathrm{mL}$ ) at room temperature. The dark solution became colorless (or light gray in some cases) after stirring for 5-73 min, an indication that the reaction was complete. The reaction mixture was charged with aqueous $\mathrm{Na}_{2} \mathrm{~S}_{2} \mathrm{O}_{3}$ ( $5 \mathrm{~mL}$ of $5 \%$ solution), followed by extraction with ether $(2 \times 15 \mathrm{~mL})$, to give a practically pure nitrile product.

CAUTION: It is known that iodine reacts with ammonia water under certain conditions to give a black powder of nitrogen triiodide monoamine $\left(\mathrm{NI}_{3} \cdot \mathrm{NH}_{3}\right)^{8}$ The dry powder explodes readily by mechanical shock, heat or irradiation. Although we did not have any incidents when handling the reactants in this study, one should avoid using excess reagent.

By comparison with the closely related methods $\mathrm{C}$ and E, our current method exhibited distinct advantages. First, we utilized the readily available ammonia water instead of ammonia gas saturated methanol. The operation of such a reaction using our method became simple and efficient. Second, we omitted $\mathrm{MeONa}$ in the reaction media so that the complication of side reactions (e.g. formation of methyl ester) found in the previous methods was avoided. In the absence of $\mathrm{MeONa}$, transformation of aldehydes to nitriles still proceeded rapidly according to our study. These two small changes did improve the yields of nitriles to a great extent, especially in the preparation of $p$-nitrobenzaldehyde $(96 \%)$, furonitrile $(88 \%)$, cinnamononitrile $(97 \%)$, and aliphatic nitriles $(>90 \%)$. It was also noted that our method was ideal for water-soluble substrates, such as 
the carbohydrates shown in Eqs. (2) and (3). Thus, 2-deoxy-D-ribose was treated with $\mathrm{I}_{2}$ in ammonia water at room temperature for $30 \mathrm{~min}$ to give an $83 \%$ yield of (3,4,5-triacetoxy)pentanenitrile ${ }^{9}$ (13) after subsequent acetylation $\left(\mathrm{Ac}_{2} \mathrm{O} /\right.$ pyridine $)$. By a similar procedure, 2,3,4,5,6-penta- $O$-benzyl-D-glucose was smoothly converted to 2,3,4,5,6-penta- $O$-benzyl-D-glucononitrile ${ }^{10}$ (14) in $85 \%$ yield.

In summary, a variety of aldehydes were successfully transformed into nitriles by treatment with iodine in ammonia water. This method is simple, economic, and environmentally benign. This method is especially useful for the transformation of water-soluble aldehydes such as carbohydrates.

\section{Acknowledgements}

We thank the National Science Council for financial support. We also thank Dr. Chun-Hung Lin (Institute of Biochemistry, Academia Sinica) for helpful discussion and providing the sample of 2,3,4,5,6-penta- $O$ benzyl-D-glucose.

\section{References}

1. (a) Mowry, D. T. Chem. Rev. 1948, 42, 250; (b) Friedrich, K.; Wallensfels, K. In The Chemistry of the Cyano Group; Rappoport, Z., Ed.; Wiley-Interscience: New York, 1970; (c) North, M. In Comprehensive Organic Functional Group Transformations; Katrizky, A. R.; Meth-Conn, O.; Rees, C. W., Eds.; Pergamon: Oxford, 1995; pp. 617-618.

2. (a) Findlay, J. A.; Tang, C. S. Can. J. Chem. 1967, 45, 1014; (b) Forey, H. G.; Datlon, D. R. J. Chem. Soc., Chem. Commun. 1973, 628; (c) Kukhar, V. P.; Pasternak, V. I. Synthesis 1974, 563; (d) Shinozaki, H.; Imaizumi, M.; Tajima, M. Chem. Lett. 1983, 929; (e) Meshram, H. M. Synthesis 1992, 943; (f) Katritzky, A. R.; Zhang, G. F.; Fan, W. Q. Org. Prep. Proc. Int. 1993, 25, 315.

3. (a) Blatter, H. M.; Lukaszewski, H.; de Stevens, G. J. Am. Chem. Soc. 1961, 83, 2203; (b) Olah, G. A.; Keumi, T. Synthesis 1979, 112 and references cited therein; (c) Dauzonne, D.; Demerseman, P.; Royer, R. Synthesis
1981, 739; (d) Saednya, A. Synthesis 1982, 190; (e) Ganboa, I.; Palomo, C. Synth. Commun. 1983, 13, 219; (f) Capdevielle, P.; Lavigne, A.; Maumy, M. Synthesis 1989, 451; (g) Bose, D. S.; Narsaiah, A. V. Tetrahedron Lett. 1998, 39, 6533; (h) Kumar, H. M. S.; Reddy, B. V. S.; Reddy, P. T.; Yadav, J. S. Synthesis 1999, 586.

4. (a) Pomeroy, J. H.; Craig, C. A. J. Am. Chem. Soc. 1959, 81, 6340; (b) Gelas-Mialhe, Y.; Vessière, R. Synthesis 1980, 1005; (c) Furukawa, N.; Fukumura, M.; Akasaka, T.; Yoshimura, T.; Oae, S. Tetrahedron Lett. 1980, 21, 761; (d) Georg, G. I.; Pfeifer, S. A. Tetrahedron Lett. 1985, 26, 2739; (e) Nishiyama, K.; Oba, M.; Watanabe, A. Tetrahedron 1987, 43, 693; (f) Suzuki, H.; Nakaya, C. Synthesis 1992, 641.

5. (a) Villemin, D.; Lalaoui, M.; Alloum, A. B. Chem. Ind. (London) 1991, 176; (b) Delgado, E.; Cano, A. C.; Garcia, O.; Alvarado, J.; Velasco, L.; Alvarez, C.; Rudler, H. Synth. Commun. 1992, 2125; (c) Feng, J.-C.; Liu, B.; Dai, L.; Bian, N.-S. Synth. Commun. 1998, 28, 3765; (d) Das, B.; Madhusudhan, P.; Venkataiah, B. Synlett 1999, 1569.

6. (a) Brackman, W.; Smit, P. J. Recl. Trav. Chim. 1963, 82, 757; (b) Parameswaran, K. N.; Friedman, O. M. Chem. Ind. (London) 1965, 988; (c) Misono, A.; Osa, T.; Koda, S. Bull. Chem. Soc. Jpn. 1966, 39, 854; (d) Sato, R.; Itoh, K.; Itoh, K.; Nishina, H.; Goto, T.; Saito, M. Chem. Lett. 1984, 1913; (e) Okimoto, M.; Chiba, T. J. Org. Chem. 1988, 53, 218; (f) Erman, M. B.; Snow, J. W.; Williams, M. J. Tetrahedron Lett. 2000, 41, 6749.

7. Misono, A.; Osa, T.; Koda, S. Bull. Chem. Soc. Jpn. 1967, 40, 2875.

8. Roesky, H. W.; Möckel, K. Chemical Curiosities; VCH: Weinheim, 1996; pp. 292-293.

9. (3,4,5-Triacetoxy)pentanenitrile $(\mathbf{1 3}):[\alpha]_{\mathrm{D}}^{25}=+7.3(c=2.5$, $\mathrm{CHCl}_{3}$ ); IR (neat) $2263 \mathrm{~cm}^{-1} ;{ }^{1} \mathrm{H}$ NMR $(300 \mathrm{MHz}$, $\left.\mathrm{CDCl}_{3}\right) \delta 2.02(3 \mathrm{H}, \mathrm{s}), 2.09(6 \mathrm{H}, \mathrm{s}), 2.65-2.81(2 \mathrm{H}, \mathrm{m})$, 4.13 ( $1 \mathrm{H}, \mathrm{dd}, J=12.5,4.2 \mathrm{~Hz}), 4.29(1 \mathrm{H}, \mathrm{dd}, J=12.5$, $3.2 \mathrm{~Hz}), 5.17-5.22(2 \mathrm{H}, \mathrm{m}) ;{ }^{13} \mathrm{C} \mathrm{NMR}\left(\mathrm{CDCl}_{3}, 50 \mathrm{MHz}\right)$ $\delta 19.6\left(\mathrm{CH}_{2}\right), 20.6\left(\mathrm{CH}_{3} \times 2\right), 20.7\left(\mathrm{CH}_{3}\right), 61.2\left(\mathrm{CH}_{2}\right), 66.4$ $(\mathrm{CH}), 70.4(\mathrm{CH}), 121.7(\mathrm{C}), 169.4(\mathrm{C}), 169.5(\mathrm{C}), 170.2$ (C). HR-FAB-MS: calcd for $\mathrm{C}_{11} \mathrm{H}_{16} \mathrm{NO}_{6}\left(\mathrm{M}^{+}+1\right) \mathrm{m} / \mathrm{z}$ 258.0978; found $m / z 258.0981$.

10. Yokoyama, M.; Kobayashi, N.; Hachiya, T.; Kubo, M.; Togo, H. Bull. Chem. Soc. Jpn. 1996, 69, 2989. The reaction of 2,3,4,5,6-penta- $O$-benzyl-D-glucose with $\mathrm{Me}_{3} \mathrm{SiN}_{3} / \mathrm{BF}_{3} \cdot \mathrm{OEt}_{2}$ in $\mathrm{CH}_{2} \mathrm{Cl}_{2}$ solution gives 2,3,4,5,6penta- $O$-benzyl-D-glucononitrile $(27 \%)$ and 1,1-diazido2,3,4,5,6-pentabenzyloxyhexane $(47 \%)$. 